ISB 2010 Session 6 : Future Directions and Challenges for Biocuration

\title{
Publishing Interactive Articles: Integrating Journals and Biological Databases
}
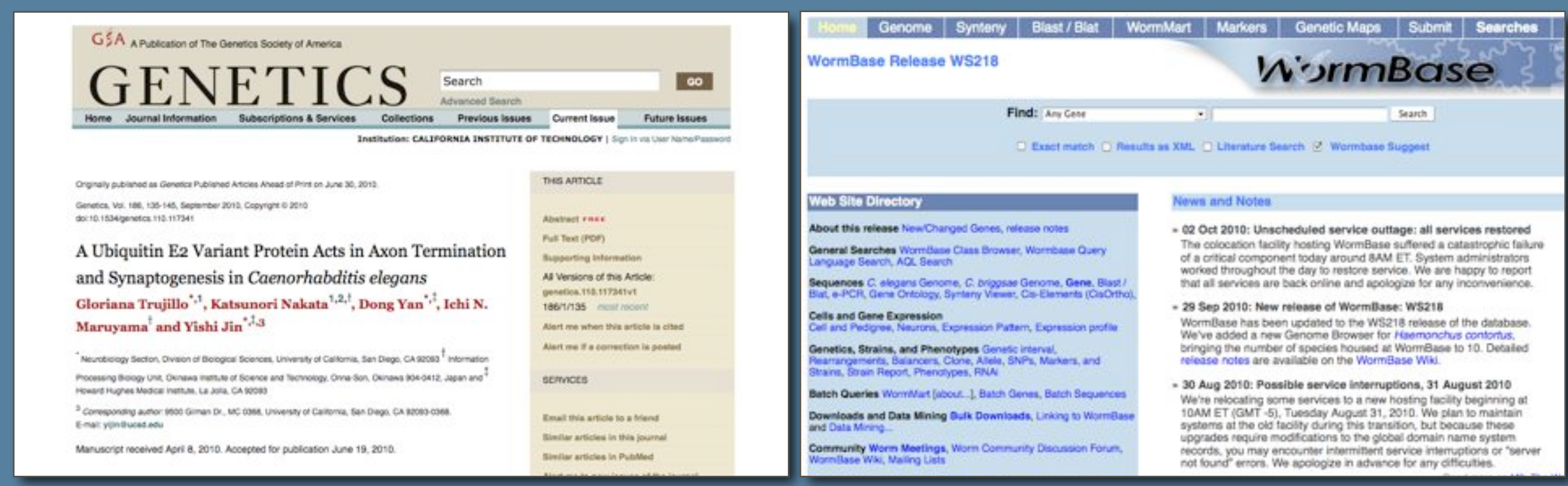

\section{Karen Yook}

Genetics Society of America, Dartmouth Journal Services,

Textpresso and WormBase 


\section{Goal: hyperlink entities in a published paper to their database resource page}

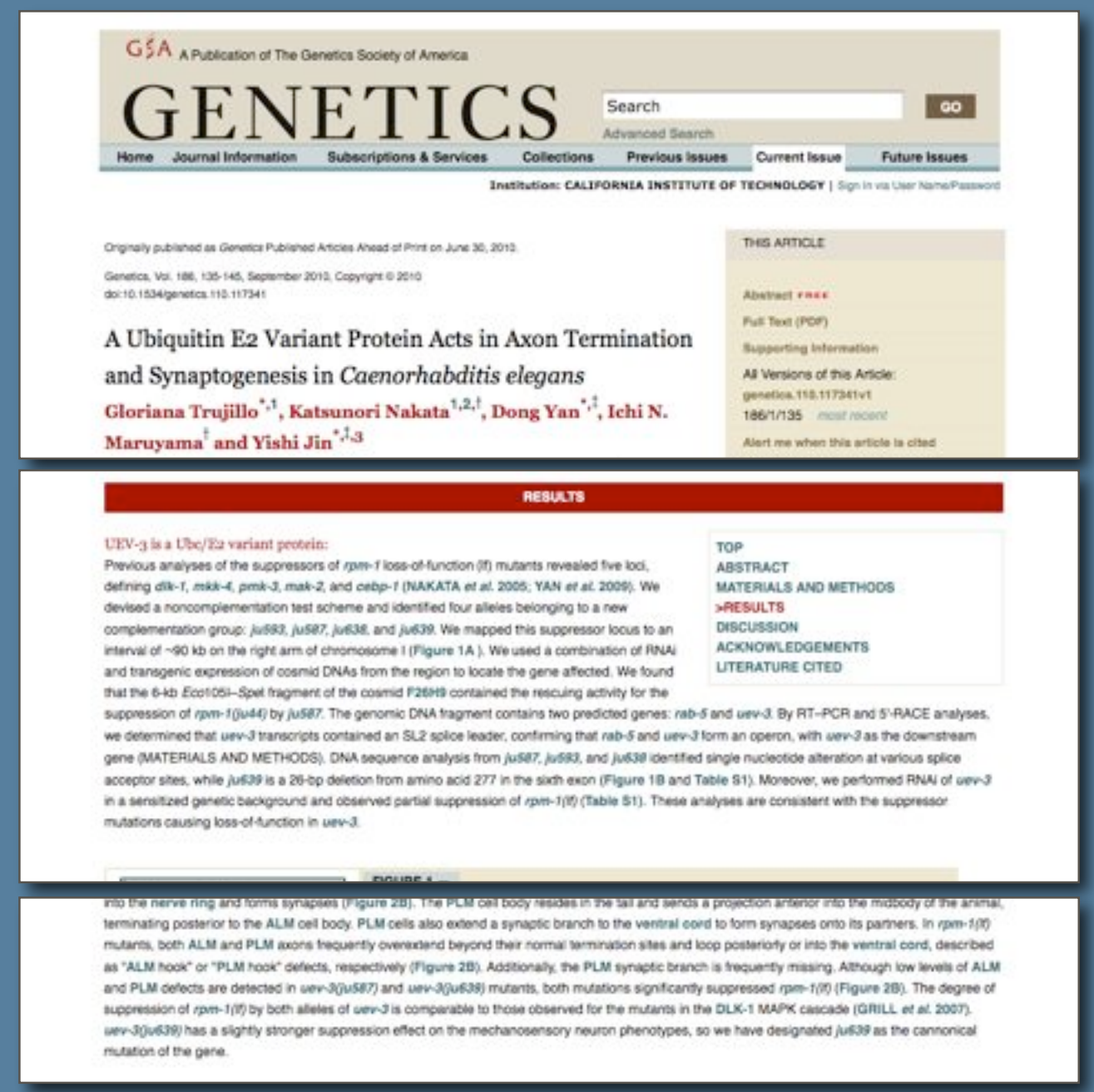




\section{Goal: hyperlink entities in a published paper to their database resource page}

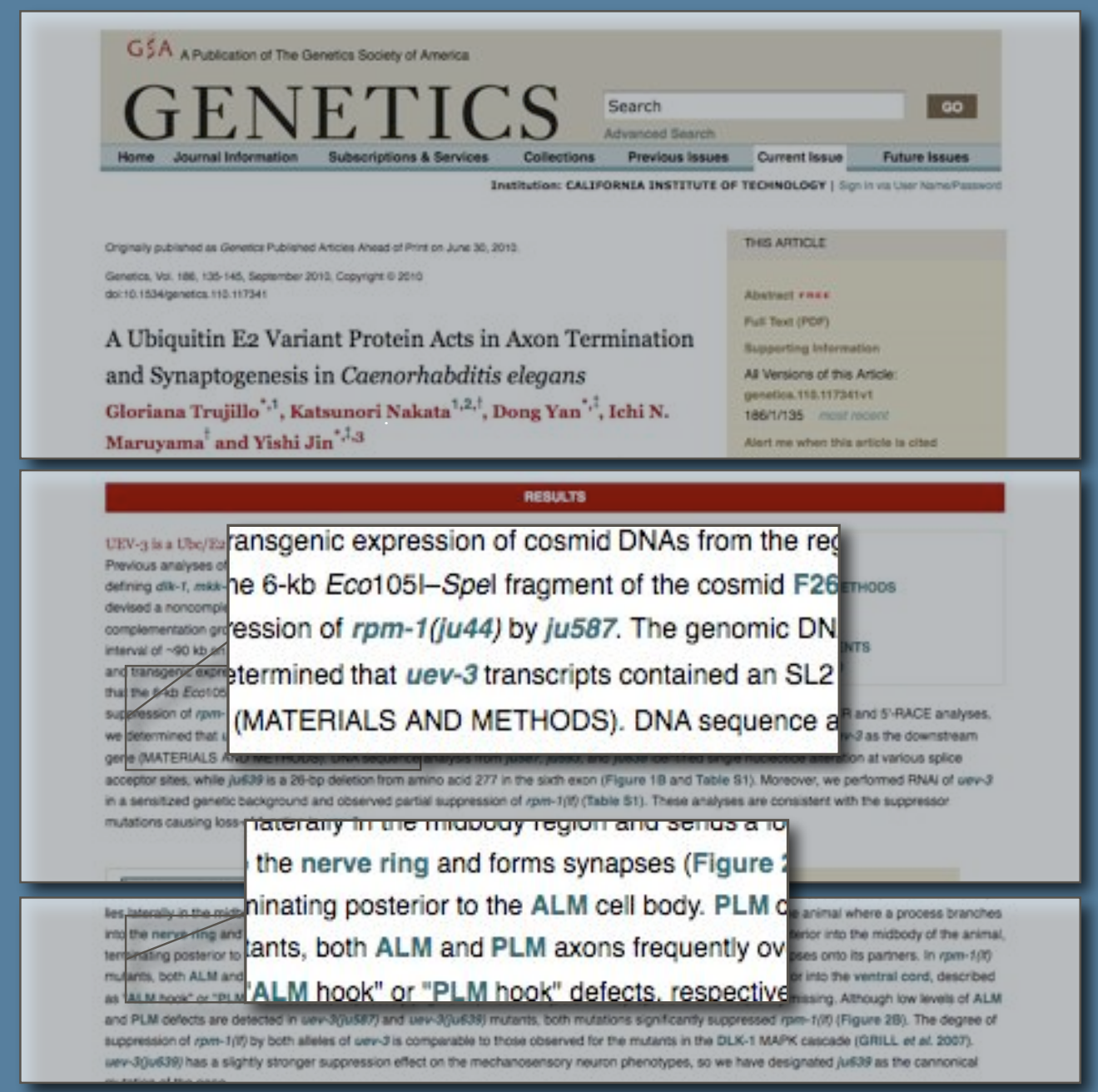




\section{Goal: hyperlink entities in a published paper to their database resource page}

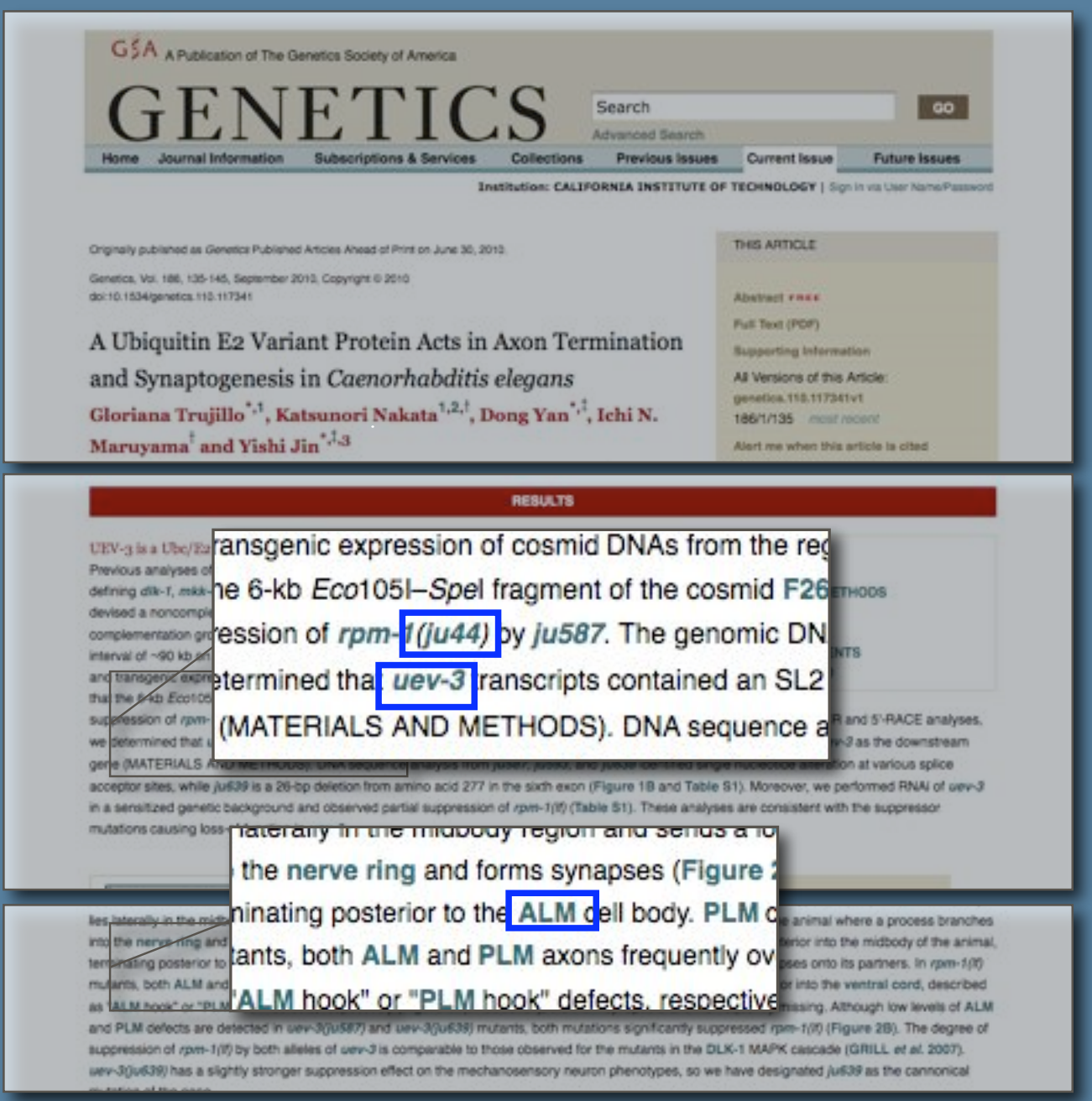




\section{Goal: hyperlink entities in a published paper to their database resource page}
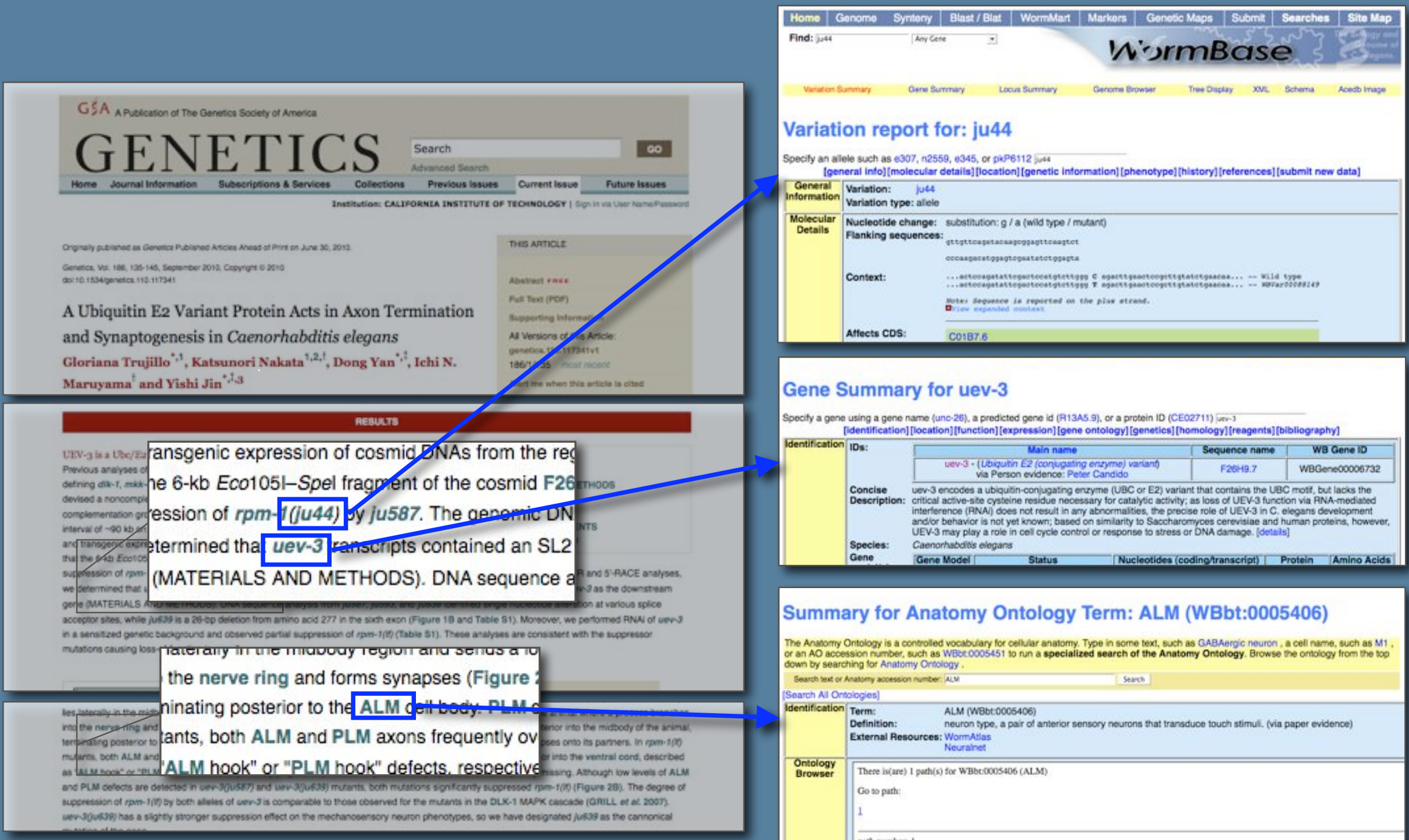

Gene Summary for uev-3
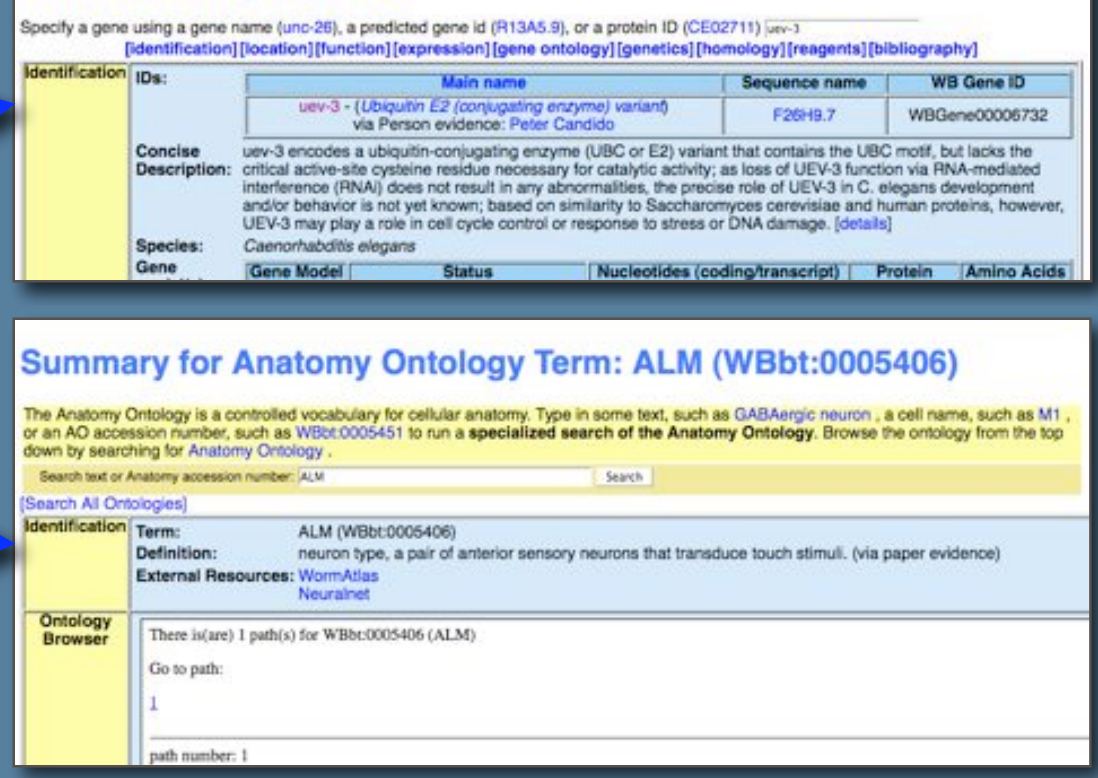


\section{GSA-Database markup pipeline}
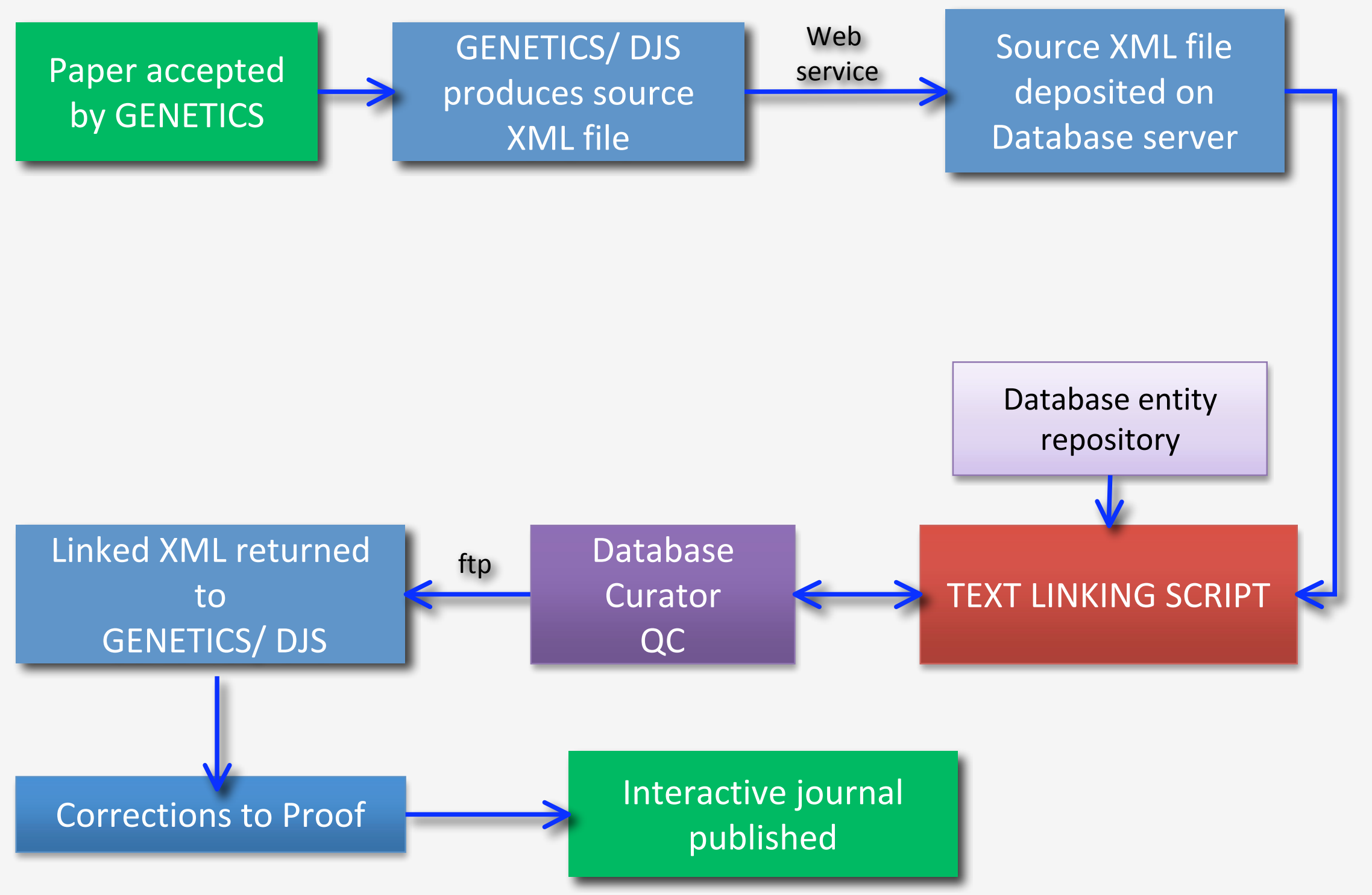


\section{What is needed for this to work}

- Textpresso -> Arun

- Source file from the journal (XML format)

- List of entities that exist in the database

- Stable database URL constructor

- Database curator for manual quality control (QC)

- Method for ensuring URL stability 


\section{What is needed:}

- List of entities that exist in the database, these are mined directly from the database (WormBase)

\begin{tabular}{l|l|l} 
Entity Class & Examples & $\begin{array}{l}\text { \# of WormBase } \\
\text { entities }\end{array}$ \\
\hline Clone & A1D10, C02H12, GAP1_10 & 204,605 \\
\hline Gene & mec-15, F25B3.5, y110a7a.10 & 537,027 \\
\hline Variation (alleles) & ad820sd, cb19860 & 274,649 \\
\hline Transgene & adEx1290, cmls6, jeln2 & 6,546 \\
\hline Rearrangement & hDp23, stDf47, sT1 & 709 \\
\hline Protein (to gene pages) & MEC-15, ABF-1 & \\
\hline Strain & BC954, IE35413 & 28,826 \\
\hline Anatomy & AWC, body wall muscle & 6,563 \\
\hline Phenotype & Muv, Lon, Dpy & 122 \\
\hline & & $1,059,047$
\end{tabular}




\section{What is needed:}

- Stable database URL constructor:

For WormBase-

http://www.wormbase.org/db/get? name=NAME;class=CLASS

NAME is the entity string (lin-11, e189, gonad)

CLASS is the class the entity belongs to (gene, variation, anatomy)

For Saccharomyces Genome Database (SGD)-

http://www.yeastgenome.org/cgi-bin/locus.fpl?dbid=SGDID

SGDID is the SGD identification for the entity 


\section{What is needed:}

- Database curator for manual quality control:

Checks all links made by the linking script

Checks for ambiguities

- adds them to an exclusion list

- provides the right entity NAME/ID

Checks for entities that did not get linked

- author writing shortcuts

- science jargon

- new entities not in the database yet 


\section{Manual QC resolves ambiguities that an automated script cannot resolve}

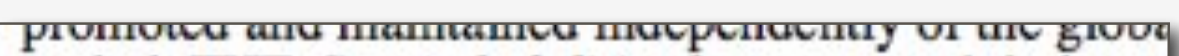
period. THE Caenorhabditis elegans gonad derives of four cells that coalesces during embryogenesis an gonad precursors (SGPs), Z1 and Z4, flanking two $\mathrm{g}$ $\mathrm{Z} 3$ (Kimble and Hirsh 1979). The SGPs undergo ver nromrame in agch sax involving axually dimornhic

\section{Microscopy:}

Images were captured using a Zeiss Imager Z1 nicroscope MRm camera and processed ing axio ision Release 4

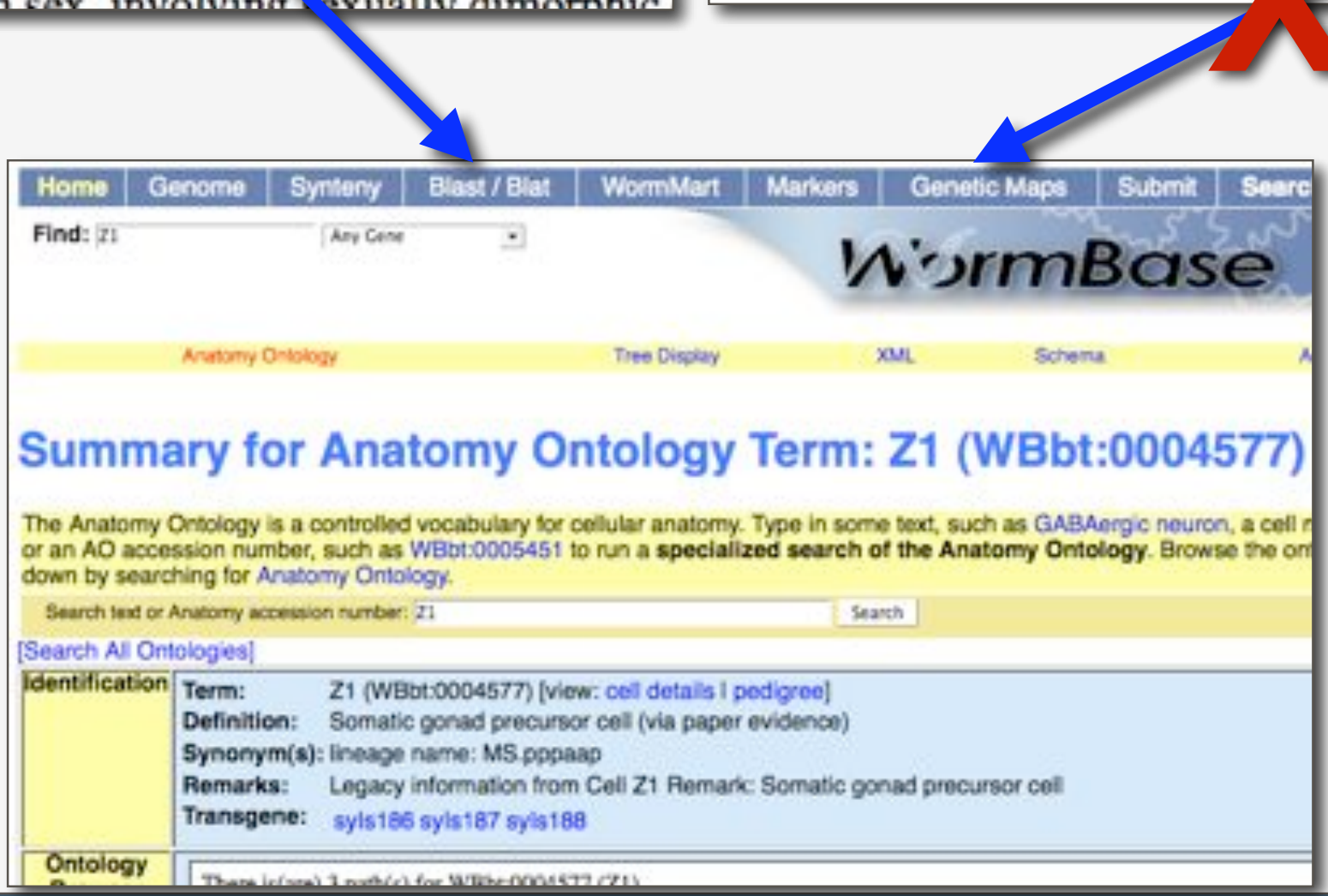




\section{Manual QC is needed to decipher authors' writing shortcuts}

Analysis of tig gene knockout alleles: Of the eight vig genes only one, sig-t, was previously analyzed through gene deletion analysis (AuRruso of al. 2002). Through generating deletion alleles by either transposon mobilization (zig $I$ ) or deletion library scpening eonducted by the $C$ elegans knockout consortia (aig-2, -3, -5, -6, -7, a nat -8), we have obtained knockout aleles for each of the so far uncharacterized, seven remaining sig genes in $C$. elegans. Each allele is a predicted molecular null allele (Figure 2C) and none affects viability or produces any
All genes are hyperlinked to their respective web page

(zig-2, zig-3, zig-5, zig-6, zig-7, 


\section{Manual QC maps informal terminology (jargon) to formal science terms}

\section{SGPs = somatic gonad precursor cells}

daughters is much more pronounced in males t pathway cause a "symmetrical sisters" phenoty is imposed on the SGPs by the global sex deter SGP sex determmation, with tra- 1 feminizing 2004). SGP sex determination is linked to cell The later phase of gonadal development involv cells enlarge and leader cells (distal tip cells in in both sexes, leading to the formation of diffe (Kimblo and Wirch 1070) Althounh SAD divic
Summary for Anatomy Ontology Term: somatic gonad precursor (WBbt:0007854)

The Anatomy Ontology is a controlled vocabulary for celluar anatomy. Type in some text, such as GABAergic neurnon, a coll name, such as acoession number, such as wabec0005451 to run a specialized search of the Anatomy Ontology. Browse the ontology from the top down

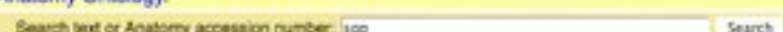

[Searech Al Comologies]

Identificmion Term: somatic gonad precursor (WBbt:0007854)

Definition: any of two colls that generate all somasc tssues of the gonsed proper (i.e. ovary or lests ) and genital of Synonym:s]:

External vas deterens). (via paper evidence)

SGP

somatic gonadal precursor col

Wormatlas

By adding acronyms and science-field jargon as synonyms to the canonical science term in the database, we capture the current language of our community while making the science more understandable to the wider science community. 


\section{What is needed:}

\section{- Method for ensuring URL stability :}

A list of entity classes, names, URLs, and webpage status is automatically generated after the final manual QC stage has been done.

This list provides an easy way to test the links for viability in the future.

\begin{tabular}{|c|c|c|c|}
\hline \multicolumn{4}{|c|}{$\begin{array}{l}\text { WB Paper ID : WBPaper00036368 } \\
\text { Genetics DOI: } 10.1534 / \text { genetics.110.115501 }\end{array}$} \\
\hline Entity dass : & Entily name & Hink & Mrosilent \\
\hline Aratomy & anterior gatid arms & 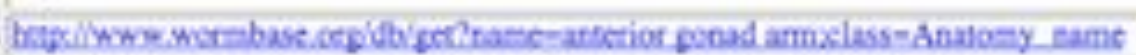 & Sive \\
\hline Anatomy & germ cell & 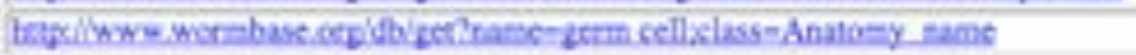 & wive \\
\hline Anatomy & Berm cetlis & 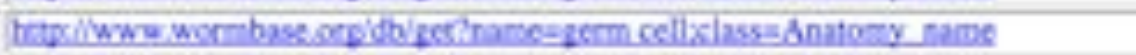 & Ino \\
\hline Anatomy & germ line & 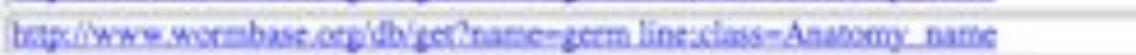 & Fine \\
\hline Anatomy & germ lifes & 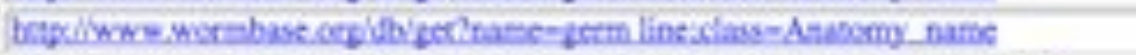 & ave \\
\hline Anatomy & spermatosyse & 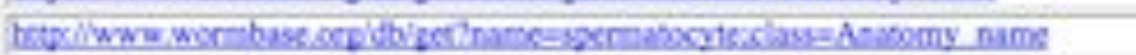 & ive \\
\hline $\mathrm{Cl} 000$ & xip 1 & 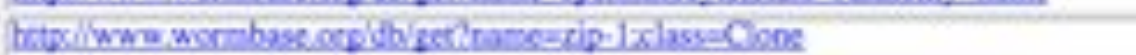 & Nove \\
\hline Genophocin ? & -2 & 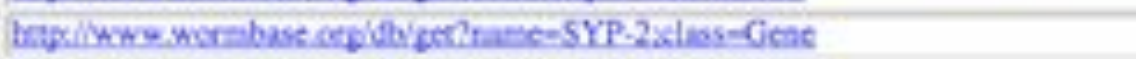 & Sve \\
\hline Genor Probein & 3 & 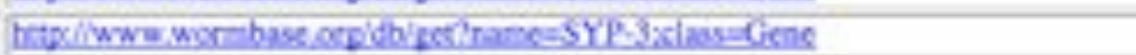 & ine \\
\hline Generthosein & 4 & 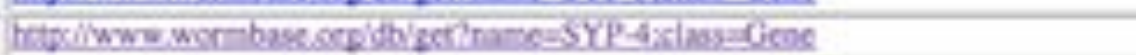 & Filent \\
\hline Gesephonein : & F26D22 2 & 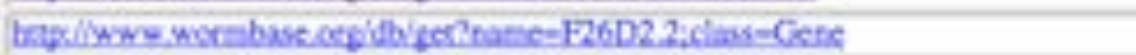 & Fine \\
\hline Gener hoosein! & HIM-3 & 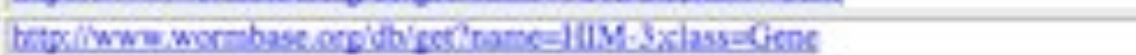 & vive \\
\hline Genophosin! & $111 \mathrm{M}-\mathrm{s}$ & 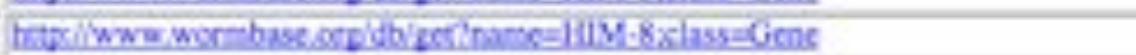 & Nive \\
\hline Geseptowein ! & RAD.51 & 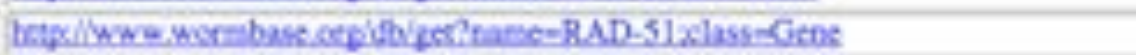 & Wive \\
\hline Genofhatein: & SYP-1 & 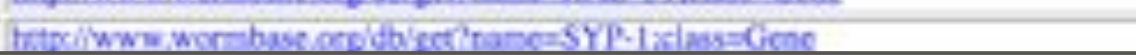 & ive \\
\hline
\end{tabular}




\section{WormBase creates silent links to entities not yet in the database}

GENETICS helps WormBase identify new entities by sending the author an entity declaration form

Manual QC identifies new entities not declared by the author

Silent links are made using the URL constructors, which will become live once the entities are added to the database 


\section{GSA-WormBase markup pipeline}

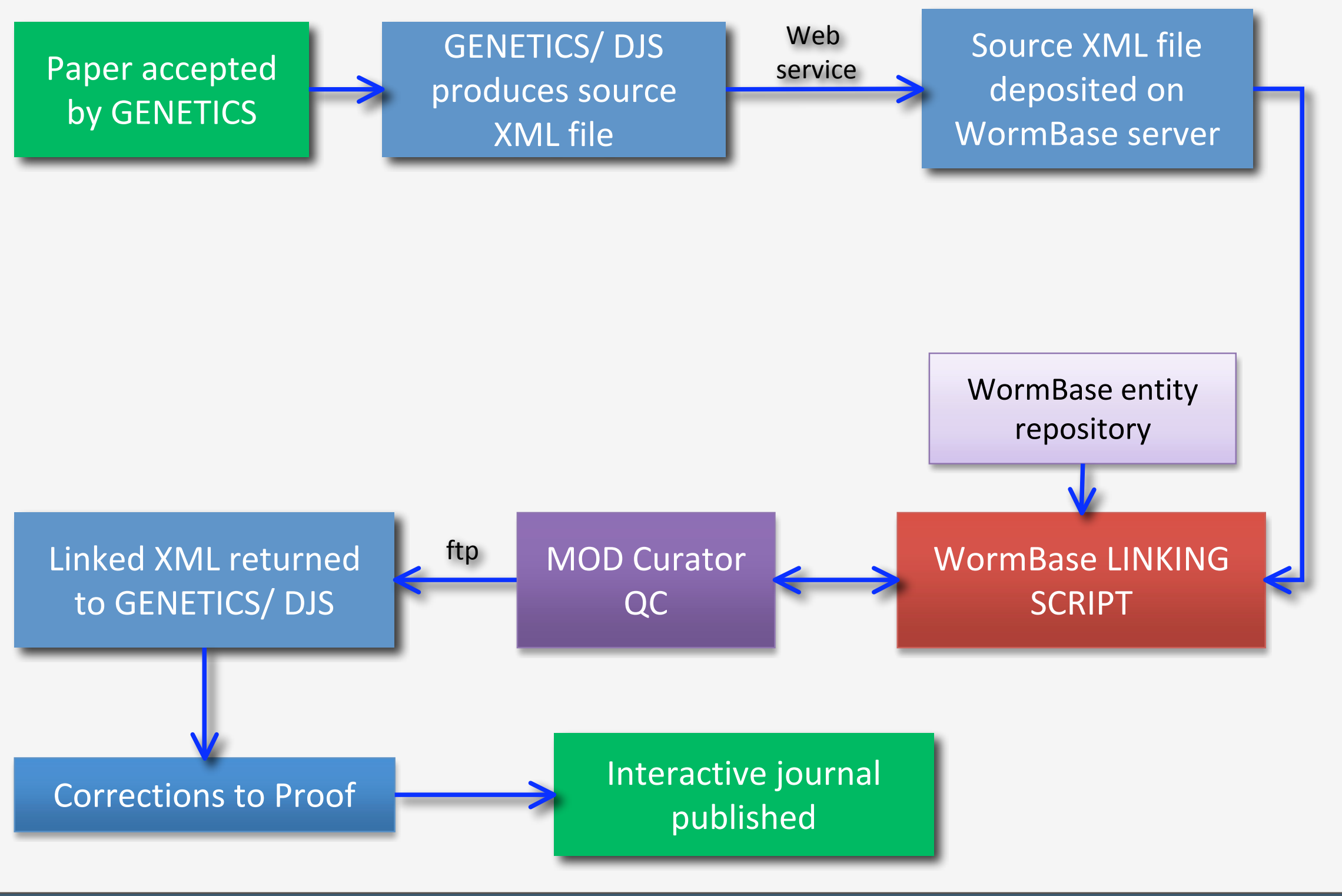




\section{GSA-WB markup pipeline includes author participation for new entities}

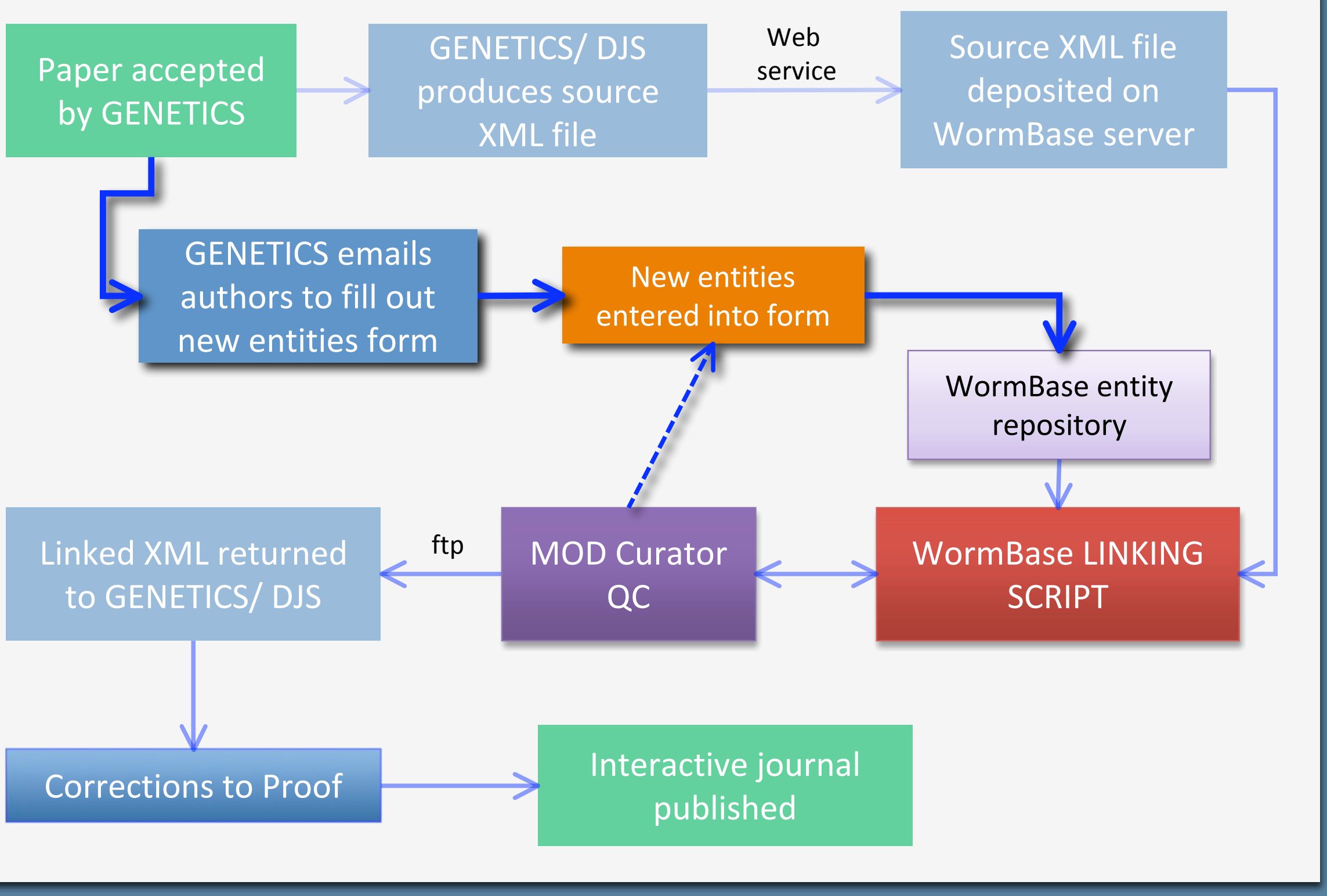




\section{Genetics sends authors an entity declaration form for WormBase}

\begin{tabular}{|c|c|c|c|c|c|c|c|c|}
\hline Fisuth & cerseme & Byntary & Biat/ Bial & WomMant & Markers & cencilemes: & Bub-it Senrehes & gis ling \\
\hline
\end{tabular}

Cengratulations on your paper being accepted by GEVEncS for publication!

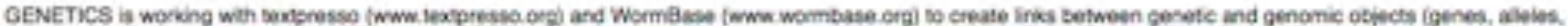

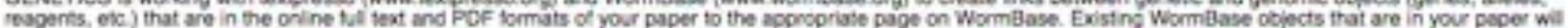

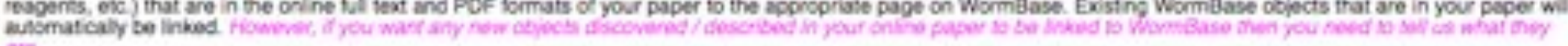

Please use the form provided beiow to enter the names of these objects. This intormation wil be sent so Wormases where these objects wil be curated and made

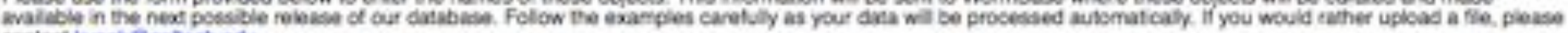
contact kyook Baboch edis

Thark you for your help.

Best Wishas.

Wombacie

mase ovi

nombaste helps wormbiate or

Cick the $7 "$ is find out more about the dara type.

Gick the "Adid information" to ocen or close the data entry bex.

This pager has already had data suem ned, leading it now.

\section{Enter new objects that you want linked in your paper :}

Genes cloned or mapped in this paper (example: odt-2 mett-10), ? Add intormation

Alleles (example: dn115, or36, u53). ? Add intormation.

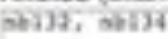

Strains (only those being sent to the CGC) (example YY166, YY173, Yr216). ? Add informution

Rearrangements fexample: hT95, cD57). ? Add intormation.

Transgenes (examplec amis4, amls\$), 7 Add informabion.

I Cell/ anatomy terms and synonyms (exarnple: accode ing sex mpoblasts). ? Add information. 


\section{Genetics sends authors an entity declaration form for WormBase}

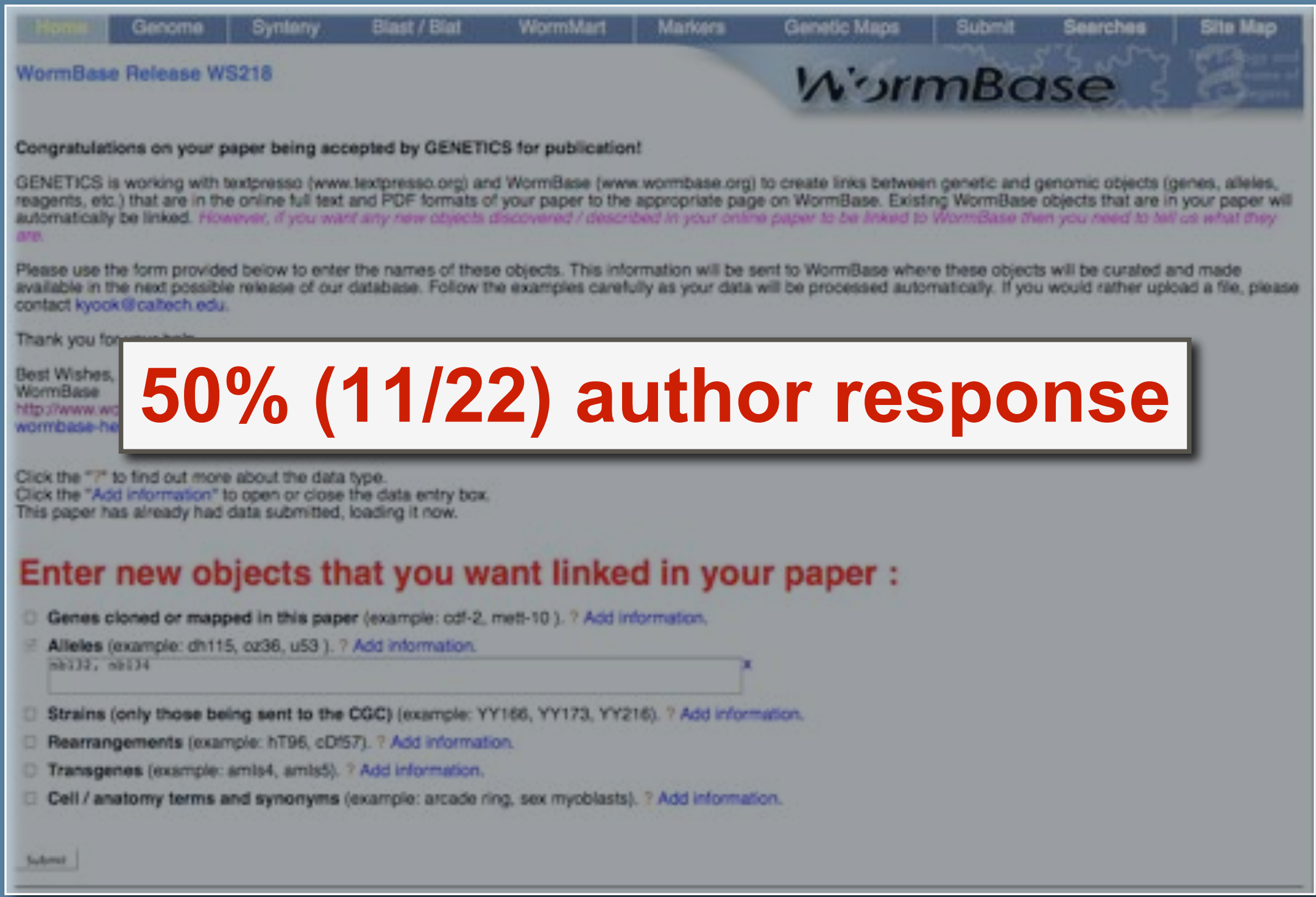




\section{Where we stand at the moment}

Caenorhabditis elegans papers marked up- 42

35 published starting in August 2009

7 waiting to be published

5 more papers accepted, still to mark up

10 entity classes marked up

All have needed manual QC

(ambiguities, new objects, copy edit errors)

Saccharomyces cerevisiae papers marked up- 23

2 entity classes marked up

Drosophila melanogaster papers will be ready to go live soon 


\section{Current challenges Linking to multiple MODs in a single paper}

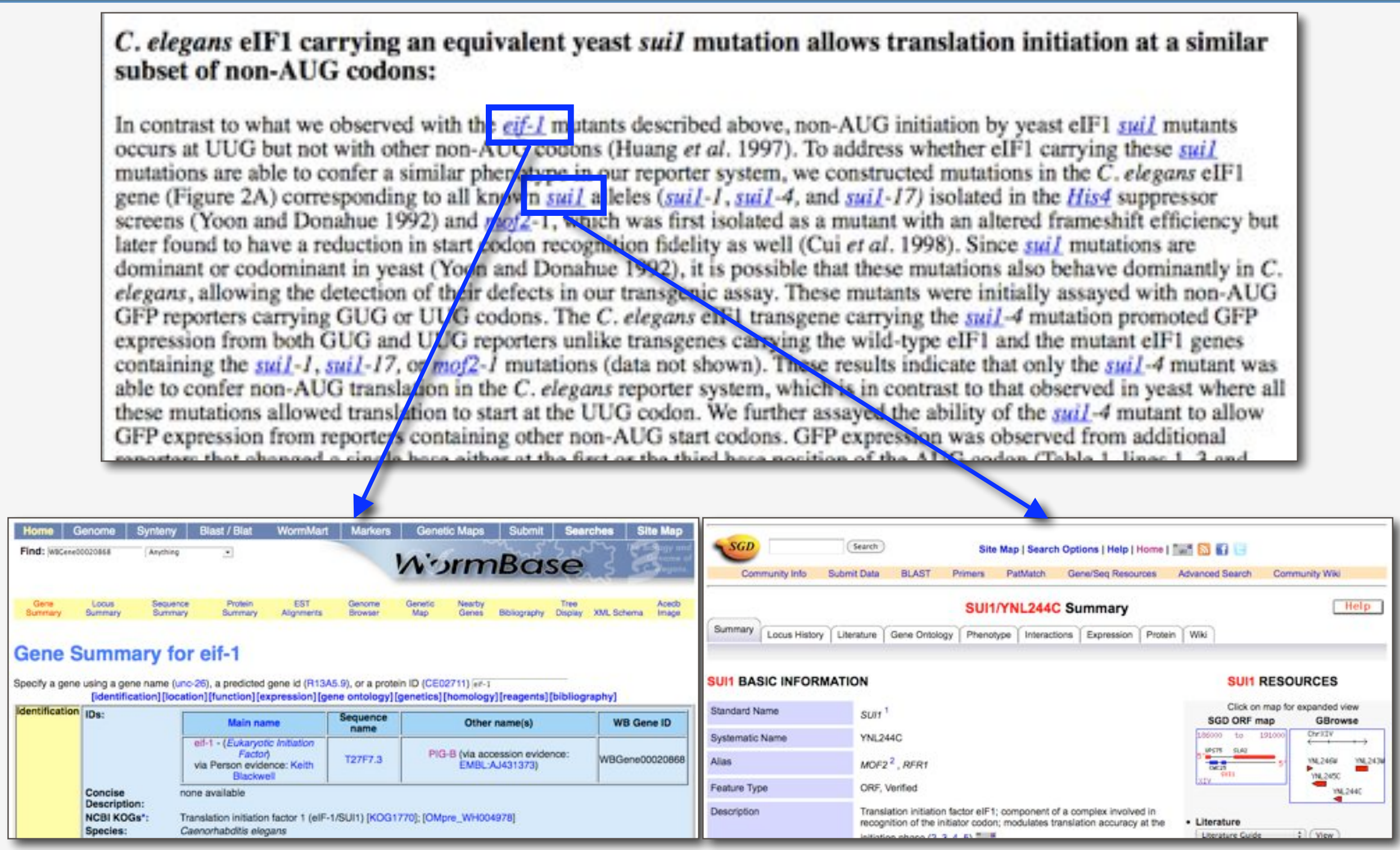




\section{Current challenges}

Linking fly genes to FlyBase

Many fly gene names are difficult to distinguish from standard everyday words, e.g., we, for, a Information-rich XML-tagged files help identify these genes

"Therefore, we tested members of major pathways that control DC such as \langle|$>$ Jun-related antigen $</ \mid>(<\mid>$ Jra $</ \mid>),<\mid>$ puckered $</ \mid>$ $(<\mid>$ puc $</ \mid>)$, and $<\mid>$ Src homology 2 ankyrin repeat tyrosine kinase $<\mid>(<\mid>$ shark $<||>)$ in the DJNK signaling pathway and $<\mid>$ thickveins $<\mid>(<\mid>$ tkv $<||>),<\mid>$ schnurri $</ \mid>(<\mid>$ shn $<||>)$, and $<$ |>zipper $</ \mid>(<\mid>$ zip $</ \mid>)$ in the TGF-\&\#x03B2; signaling pathway. Furthermore, we tested additional genes involved in DC such as $<\mid>$ u-shaped $</ \mid>(<\mid>$ ush $</ \mid>),<\mid>$ Epidermal growth factor receptor $</ \mid>(<\mid>$ Egfr $</ \mid>),<\mid>$ Protein kinase related to protein kinase $\mathbf{N}</|>(<|>\mathbf{P k n}</|>),<|>\mathbf{s c a b}</ \mid>(<|>\mathbf{s c b}</|>)$, and $<\mid>$ Rho1 $</ \mid>\ldots$..." 


\section{Benefits of published text markup}

For the community:

Less time to get to the correct database page

Transparency of science jargon

Term ambiguities are dealt with before publication

For the journal:

Becomes a live portal to science information

For the author:

Extra pair of eyes for proofing their document

Data enter the database faster

For the database:

Increase depth and accuracy of data in the database Get information before publication Resolve conflicts in term use before publication 


\section{Future challenges}

- Extending this pipeline to other MODs / Databases

- Extending this pipeline to other journals

- standardized XML format can help

- Increasing the number of Databases and entity classes linked in a multi-organism paper

- Fixing broken links

- Re-marking up publications 


\section{Acknowledgements}

\section{n'ormbase}

Textpresso

Arun Rangarajan

Karen Yook

Juancarlos Chan

Hans-Michael Muller

Paul W. Sternberg (HHMI)
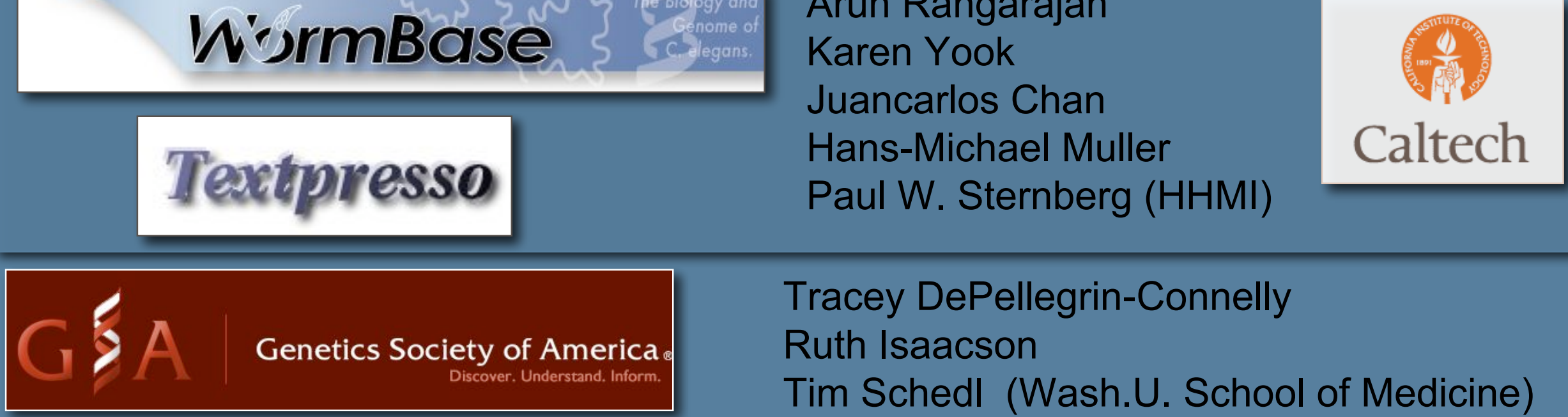

Tracey DePellegrin-Connelly

Ruth Isaacson

Tim Schedl (Wash.U. School of Medicine)

DARTMOUTH JOURNAL SERVICES

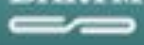

Stephen Haenel

Lolly Otis

Sharon Faelten

$S G D$

Saccharomyces Genome Database

Marek S. Skrzypek, J. Michael Cherry (Stanford University School of Medicine)

Cov FlyBase

William M. Gelbart (Harvard University)

Thom Kaufman, Kathy Matthews (Indiana University)

Raymund Stefancsik, Steven Marygold (Cambridge University, UK) 